\title{
Single and staged laser interstitial thermal therapy ablation for cortical tubers causing refractory epilepsy in pediatric patients
}

\author{
Zulma Tovar-Spinoza, MD, Robert Ziechmann, MD, and Stephanie Zyck, MD \\ Department of Neurosurgery, SUNY Upstate Medical University, Syracuse, New York
}

\begin{abstract}
OBJECTIVE Magnetic resonance-guided laser interstitial thermal therapy (MRgLITT) is a novel, minimally invasive treatment for the surgical treatment of epilepsy. In this paper, the authors report on clinical outcomes for a series of pediatric patients with tuberous sclerosis complex (TSC) and medication-refractory epileptogenic cortical tubers.

METHODS A retrospective chart review was performed at SUNY Upstate Golisano Children's Hospital in Syracuse, New York. The authors included all cases involving pediatric patients ( $<18$ years) who underwent MRgLITT for ablation of epileptogenic cortical tubers between February 2013 and November 2015.

RESULTS Seven patients with cortical tubers were treated (4 female and 3 male). The patients' average age was 6.6 years (range 2-17 years). Two patients had a single procedure, and 5 patients had staged procedures. The mean time between procedures in the staged cases was 6 months. All of the patients had a meaningful reduction in seizure frequency as reported by Engel and ILAE seizure outcome classifications, and most (71.4\%) of the patients experienced a reduction in AED burden. Three of the 4 patients who presented with neuropsychiatric symptoms had some improvement in these domains after laser ablation. No perioperative complications were noted. The mean duration of follow-up was 19.3 months (range 4-49 months).
\end{abstract}

CONCLUSIONS Laser ablation represents a minimally invasive alternative to resective epilepsy surgery and is an effective treatment for refractory epilepsy due to cortical tubers.

https://thejns.org/doi/abs/10.3171/2018.6.FOCUS18228

KEYWORDS MRgLITT; tuberous sclerosis complex; epilepsy; laser; minimally invasive surgery; pediatric

$\mathrm{T}$ uberous sclerosis complex (TSC) is a multisystem disorder that variably involves the brain, skin, kidney, heart, and lungs. "Two-hit" inactivation of the $T S C 1$ or TSC 2 tumor suppressor genes results in the growth of generally benign tumors in these organs. Epilepsy is the most common clinical manifestation of TSC and is found in as many as $90 \%$ of cases. ${ }^{34}$ Epileptogenesis has been theorized to result from different morphological and molecular abnormalities observed in the cortical tubers and the perituberal cortex. ${ }^{29}$ Structural abnormalities in the central nervous system associated with tuberous sclerosis include cortical tubers, heterotopic gray and white matter, and associated white matter tract abnormalities. ${ }^{14,33}$ Subependymal giant cell astrocytomas (SEGAs) are also a hallmark feature. ${ }^{14}$ While the exact pathogenesis of epilepsy in this patient population is not well understood, structural abnormalities are thought to play a role., ${ }^{7,37}$

Epilepsy in TSC is a significant source of personal and financial burden. Furthermore, it is often refractory to medical treatment. Children with epilepsy have higher rates of injury (e.g., burns, fractures), mortality (e.g., drowning, sudden unexpected death in epilepsy [SUDEP]), and behavioral problems (e.g., anxiety, attention deficit disorder). ${ }^{18,31,35}$ Earlier onset of seizures is correlated with

ABBREVIATIONS AED = antiepileptic drug; EEG = electroencephalography; FLAIR = fluid-attenuated inversion recovery; ILAE = International League Against Epilepsy; LITT = laser interstitial thermal therapy; MRgLITT = MR-guided LITT; PET = positron emission tomography; SEGA = subependymal giant cell astrocytoma; SPECT = single photon emission computed tomography; TSC = tuberous sclerosis complex; VEEG = video-EEG. ACCOMPANYING EDITORIAL DOI: 10.3171/2018.7.FOCUS18348.

SUBMITTED May 4, 2018. ACCEPTED June 28, 2018.

INCLUDE WHEN CITING DOI: 10.3171/2018.6.FOCUS18228. 


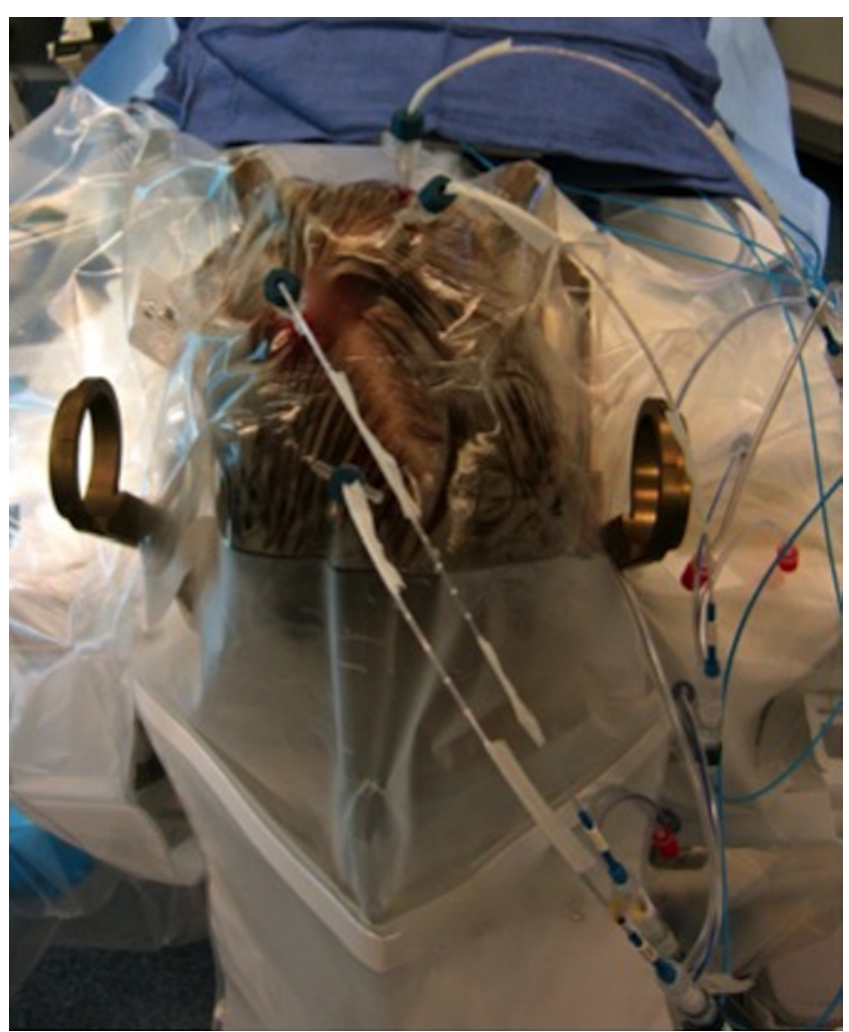

FIG. 1. Patient 4. Photograph showing multiple lasers applied for treatment of multiple tubers in a single session of MRgLITT.

a substantial decline in developmental and behavioral functioning, emphasizing the need for timely and effective intervention. ${ }^{39}$

For cases in which the epileptogenic zone is associated with a tuber or multiple tubers, single or staged resection is the current standard of care. ${ }^{8}$ However, morbidity for each admission in staged resective surgery has been reported as $2 \%$ for neurological deficits, $1.5 \%$ for CNS or flap infections, $5.5 \%$ for positive cultures, and $3 \%$ for wound complications (many requiring surgical revision). ${ }^{15,16}$

Magnetic resonance-guided laser interstitial thermal therapy (MRgLITT) is a less invasive alternative to treat epileptogenic foci such as cortical tubers without requiring an open surgery. We present our initial experience using minimally invasive MRgLITT to treat 7 pediatric patients with intractable epilepsy due to TSC.

\section{Methods \\ Study Design}

We performed a retrospective chart review at SUNY Upstate Golisano Children's Hospital $(\mathrm{GCH})$ for patients up to 18 years of age who received MRgLITT for ablation of epileptogenic cortical tubers between February 2013 and November 2015. The GCH research ethics board granted approval for this study.

\section{Patient Selection}

All patients were deemed to have seizures that were refractory to treatment with multiple antiepileptic drugs
(AEDs). All patients received a phase 1 epilepsy surgery evaluation including video-electroencephalography (VEEG), volumetric MRI, and diffusion tensor imaging. Also, positron emission tomography (PET), and/or single photon emission computed tomography (SPECT) and EEG high-frequency oscillation analysis were performed if indicated. The most epileptogenic tubers on these evaluations were chosen for ablation. If there were multiple epileptogenic tubers, the institution's multidisciplinary epilepsy team selected the most active targets that would correlate clinically with recorded seizures.

\section{Surgical Technique}

The surgical technique is similar to that which has been previous described. ${ }^{37}$ The ablative procedures were performed stereotactically using Visualase (Visualase, Inc.) or NeuroBlate (Monteris Inc.) under general anesthesia. Technological factors described in prior studies and institutional preference dictated which system was used in our series. ${ }^{37,38}$ Patients were given local anesthesia at the sites of pin fixation and then placed in a Leksell head frame (Elekta AB). After the head frame was applied, the patients were transferred to the MRI suite to obtain imaging for frame-based stereotactic guidance. The cortical tubers were localized by T1-weighted MRI and T2-weighted fluid-attenuated inversion recovery (FLAIR) images, and all images were transferred to a Stryker Navigation imageguided surgery workstation or BrainLab iPlan software for co-registration with the images referencing the Leksell frame coordinate system. On return to the operating room, the arc was attached to the frame and appropriate coordinates were set. The trajectories for ablation were planned using the navigation software to ablate the tuber and surrounding perituberal cortex.

Once the placement of the laser probe on the planned target was confirmed by MRI, additional laser applicators could then be placed (Fig. 1). The Leksell frame was repositioned as needed using coordinates to target the other epileptogenic tubers. For each lesion, the laser probe was moved along the planned trajectory to ablate the cortical tuber and disconnect it from the surrounding white matter using MRI guidance. After ablation of the epileptogenic foci, postoperative T2 FLAIR and post-gadolinium T1 MRI scans were obtained to show the extent of ablation. All patients underwent post-ablation overnight VEEG. For the patients with staged procedures, a new presurgical evaluation was performed at least 3 months later to identify the epileptogenic tuber(s) before their next ablation, and confirm the lack of epileptogenesis in the already ablated tubers.

\section{Results}

Seven patients ( 4 female and 3 male) were treated. Their demographic and clinical data are summarized in Table 1. The patients' average age was 6.6 years (range 2-17) at the time of initial treatment. All patients underwent routine presurgical evaluations with volumetric MRI and VEEG monitoring for surgical planning. One patient had undergone a prior laser ablation for an intraventricular SEGA.

Procedural details for each patient and operation are 
TABLE 1. Demographic and clinical characteristics of the 7 TSC pediatric patients with refractory epilepsy treated with MRgLITT

\begin{tabular}{|c|c|c|c|c|c|c|c|}
\hline Characteristic & Pt 1 & Pt 2 & Pt 3 & $\mathrm{Pt} 4$ & Pt 5 & Pt 6 & Pt 7 \\
\hline $\begin{array}{l}\text { Age in yrs at } 1 \text { st ablation of } \\
\text { cortical tuber }\end{array}$ & 6 & 2 & 17 & 8 & 4 & 7 & 2 \\
\hline $\begin{array}{l}\text { Target identification via } \\
\text { extracranial EEG }\end{array}$ & Yes & Yes & Yes & Yes & Yes & Yes & Yes \\
\hline Location of target & $\begin{array}{l}\text { St 1: It fr/temp; } \\
\text { St 2: It occ }\end{array}$ & $\begin{array}{l}\text { St 1: rt temp, It par; St 2: It } \\
\text { occ; St 3: rt occ; St 4: rt par }\end{array}$ & Lt par & $\begin{array}{l}\text { St 1: It temp; } \\
\text { St 2: rt par }\end{array}$ & $\begin{array}{l}\text { St 1: rt fr, It fr/par; St 2: } \\
\text { rt par, It temp/par }\end{array}$ & $\begin{array}{l}\text { St 1: rt fr/temp; } \\
\text { St 2: It fr/temp }\end{array}$ & Rt occ \\
\hline $\begin{array}{l}\text { Previous cranial surgery } \\
\text { related to target }\end{array}$ & No & No & No & No & No & No & No \\
\hline $\begin{array}{l}\text { Previous cranial surgery } \\
\text { not related to target }\end{array}$ & Yes $^{*}$ & No & No & No & No & No & No \\
\hline
\end{tabular}

$\mathrm{Fr}=$ frontal; occ = occipital; par = parietal; $\mathrm{pt}=$ patient; $\mathrm{St}=$ stage temp = temporal.

* LITT of subependymal giant cell astrocytoma 16 months previously.

summarized in Table 2. Two patients had a single procedure while 5 patients had staged procedures. The mean time between procedures in this latter group was 6 months. The mean anesthesia time was 5.3 hours (range 3-10 hours). Technical issues with MRI led to an increased anesthesia time of $9-10$ hours in 2 patients. The number of laser trajectories ranged from 1 to 4 (mean 2.4). A postoperative stay in the ICU was routinely scheduled in all cases, and patients received steroids during and after the operations per routine protocol. The hospital length of stay ranged from 1 to 7 days (mean 2.6 days).

For all of our patients, the laser applicators were accurately placed, and successful ablation of the target lesion was achieved as demonstrated by post-ablation FLAIR and contrast-enhanced T1-weighted MRI. The total volume of the ablated lesions ranged from 2.9 to $29.5 \mathrm{~cm}^{3}$ (mean $11.1 \mathrm{~cm}^{3}$ ). All of our patients had at least worthwhile improvement according to the Engel seizure and the International League Against Epilepsy (ILAE) outcome scores (Table 3), and 3 patients (43\%) achieved seizure freedom. Five of our patients were able to reduce their use of AEDs. Three of 4 patients who presented with neuropsychiatric symptoms had some improvement in these domains after laser ablation. No perioperative complications or 30-day readmissions were noted. The mean duration of clinical follow-up was 19.3 months (range 4-49 months). The outcomes for each patient and procedure are summarized in Table 3.

\section{Illustrative Case}

This 6-year-old boy (patient 1 in Table 1) with TSC and known SEGA previously treated with laser ablation and everolimus presented with intractable generalized tonicclonic seizures. He had an initial diagnosis of infantile spasms at 6 weeks of age. After multiple trials of AEDs, his seizures had been controlled for some time with a combination of lamotrigine and zonisamide. However, at the

TABLE 2. Procedural details for each patient and procedure

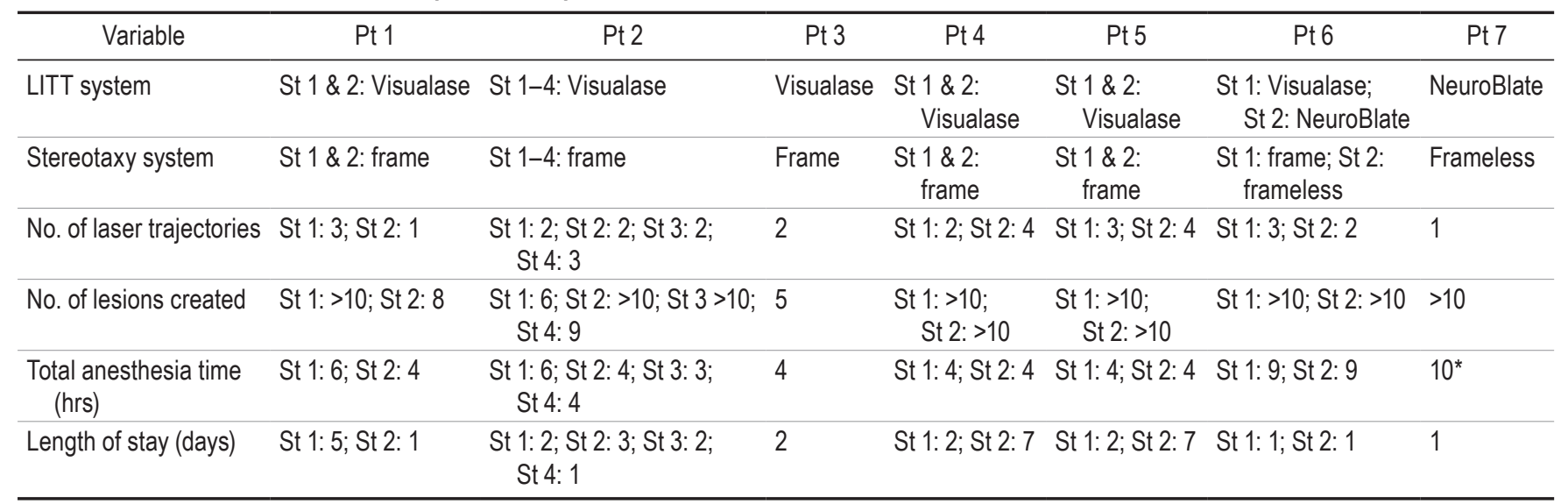

Complete disconnection was achieved for all targets in all cases. All patients were cared for in the ICU after the procedures (planned ICU stay) and were administered steroid medication the day of surgery and postoperatively according to the predetermined routine regimen. There was no unplanned postoperative steroid use.

* Technical issues with the MRI. 
TABLE 3. Patient outcomes after each MRgLITT procedure

\begin{tabular}{|c|c|c|c|c|c|c|c|}
\hline Variable & Pt 1 & Pt 2 & Pt 3 & Pt 4 & Pt 5 & Pt 6 & Pt 7 \\
\hline No. of AEDs preop & St $1 \& 2: 3$ & $\begin{array}{l}\text { St } 1: 4 ; \text { St } 2 \& 3: 3 ; \\
\quad \text { St } 4: 2\end{array}$ & 5 & St 1: 3; St 2: 4 & St $1 \& 2: 4$ & St $1 \& 2: 4$ & 1 \\
\hline $\begin{array}{l}\text { No. of } A E D s \text { at FU after each } \\
\text { procedure }\end{array}$ & St 1: 3; St 2: 1 & St $1 \& 2: 3 ;$ St $3 \& 4: 2$ & 4 & St 1: 3; St 2: 4 & St 1: 5; St 2: 4 & St $1: 4 ;$ St $2: 3$ & 0 \\
\hline Post-ablation ILAE outcome class & St 1: 4; St 2: 2 & St 1: 3; St 2-4: 2 & 4 & St 1: 2; St 2: 3 & St 1: 2; St 2: 3 & St $1 \& 2: 3$ & 1 \\
\hline Post-ablation Engel class & St 1\& 2: II & St 1-3: II; St 4: I & II & St 1: II; St 2: III & St 1\& 2: III & St 1: II; St 2: I & I \\
\hline $\begin{array}{l}\text { Post-ablation cranial surgery } \\
\text { related to target }\end{array}$ & Multi-stage ablation & Multi-stage ablation & No & $\begin{array}{l}\text { Multi-stage } \\
\text { ablation }\end{array}$ & $\begin{array}{l}\text { Multi-stage } \\
\text { ablation }\end{array}$ & $\begin{array}{l}\text { Multi-stage } \\
\text { ablation }\end{array}$ & No \\
\hline $\begin{array}{l}\text { Total vol of ablation on 3-mo FU } \\
\qquad \mathrm{MRI}\left(\mathrm{cm}^{3}\right)\end{array}$ & St 1: 9.6; St 2: 7.7 & $\begin{array}{l}\text { St 1: } 22.5 ; \text { St } 2: 3.2 \\
\text { St 3: } 2.9 ; \text { St } 4: 3.5\end{array}$ & 16.2 & $\begin{array}{l}\text { St 1: } 3.8 ; \text { St } 2 \text { : } \\
\quad 20.1\end{array}$ & $\begin{array}{l}\text { St 1: 14.6; St 2: } \\
\text { MRI NA }\end{array}$ & $\begin{array}{l}\text { St 1: } 29.5 \\
\text { St 2: } 2.6\end{array}$ & 7.5 \\
\hline $\begin{array}{l}\text { Time of max response confirmed } \\
\text { w/ MRI }\end{array}$ & $\begin{array}{l}\text { St 1: } 25 \text { mos; St 2: } \\
19 \text { mos }\end{array}$ & 20 mos for all & $21 \mathrm{mos}$ & $\begin{array}{l}\text { St 1: } 10 \text { mos; } \\
\text { St 2: } 12 \text { mos }\end{array}$ & $\begin{array}{l}\text { St 1: } 4 \text { mos; } \\
\text { St 2: MRI NA }\end{array}$ & $\begin{array}{l}\text { St 1: } 8 \text { mos; } \\
\text { St 2: } 9 \text { mos }\end{array}$ & $5 \mathrm{mos}$ \\
\hline $\begin{array}{l}\text { Time of most recent FU MRI from } \\
\text { 1st ablation }\end{array}$ & $49 \mathrm{mos}$ & $36 \mathrm{mos}$ & $21 \mathrm{mos}$ & $18 \mathrm{~m}$ & $12 \mathrm{mos}$ & $29 \mathrm{mos}$ & $13 \mathrm{mos}$ \\
\hline
\end{tabular}

FU = follow-up; $N A=$ not available.

All patients had improvement in the targeted type after each procedure. Follow-up MRI showed that all treated tubers responded to laser ablation. None of the patients had any complications related to the procedures, required readmission within 30 days, or underwent any post-ablation cranial surgery unrelated to the target.

time that he was referred to the neurosurgery clinic, he had developed breakthrough seizures and severe self-harming behavior, and his medication regimen had been increased to 3 AEDs without successful seizure control. Brain MRI showed bilateral tubers as well as a SEGA of the right lateral ventricle (Fig. 2). VEEG demonstrated multiple seizures corresponding with multifocal spikes and sharp waves involving the left frontal and temporal regions. The patient underwent 2 staged MRgLITT procedures. The first staged procedure targeted the left frontal and temporal cortical tubers (Fig. 3 upper). Postoperative MRI after 3 months' duration showed satisfactory ablation volume of the targets (Fig. 4). The patient initially had clinical improvement of his seizures, however, about a year later he began having increased neuropsychiatric symptoms including agitation, which prompted further workup. Follow up VEEG localized seizure activity to the left occipital lobe, and he underwent an additional MRgLITT of the corresponding left occipital cortical tuber (Fig. 3 lower).
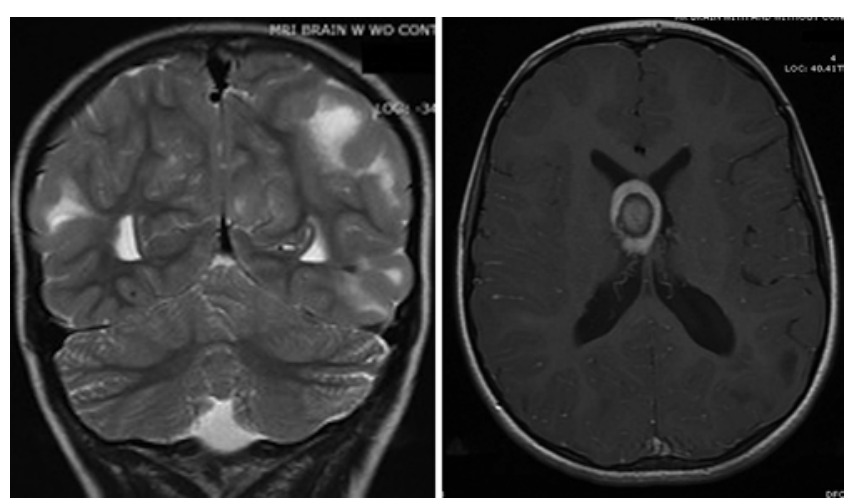

FIG. 2. Illustrative case (patient 1). Left: Preoperative coronal T2 FLAIR MR image changes demonstrating hyperintense left frontal and temporal cortical tubers. Right: Axial MR image showing previously ablated SEGA.
Following this series of ablations, the patient has been able to wean to lamotrigine only and has been seizure free for 3 years. He has had improvement in his self-aggressive behavior, which is now relatively well controlled with clonidine and risperidone. He has also made significant progress with respect to developmental milestones.

\section{Discussion}

Several studies have been published to clarify epileptogenicity in TSC, widening the pathophysiological hypothesis of its onset. ${ }^{21}$ As stated previously, epileptogenesis is thought to be the result of different structural and molecular abnormalities observed in the cortical tubers and the perituberal cortex. ${ }^{30}$ Furthermore, certain morphological features in tubers may predispose to seizures: abnormal cerebral cortical cytoarchitecture, associated astrocytic proliferation, the presence of calcifications, unusual vascular anatomy, edema, altered neurotransmitter receptor expression, and balance between cell proliferation and death. $^{21}$

Correspondence between lesions seen on MRI and electroencephalographic activity support the role of cortical tubers as epileptogenic foci. ${ }^{32}$ However, it is uncertain whether it is the tubers themselves or the influence of the tubers on surrounding neural networks that causes seizures. Some studies have identified foci in the perituberal cortex rather than the tubers themselves. ${ }^{1,14}$ It has also been observed that not all tubers generate seizures..$^{14}$ Our cases represent the ablation of both the cortical tubers and perituberal cortex in those tubers that proved to be epileptogenic on the standard evaluations. One limitation of our study is that we did not use invasive EEG monitoring to localize our surgical targets. However, intracranial EEG using stereoelectroencephalography (SEEG) may prove to be useful in the future to more accurately define seizure foci and propagation in a minimally invasive fashion. One could also consider converting a trajectory from SEEG to 

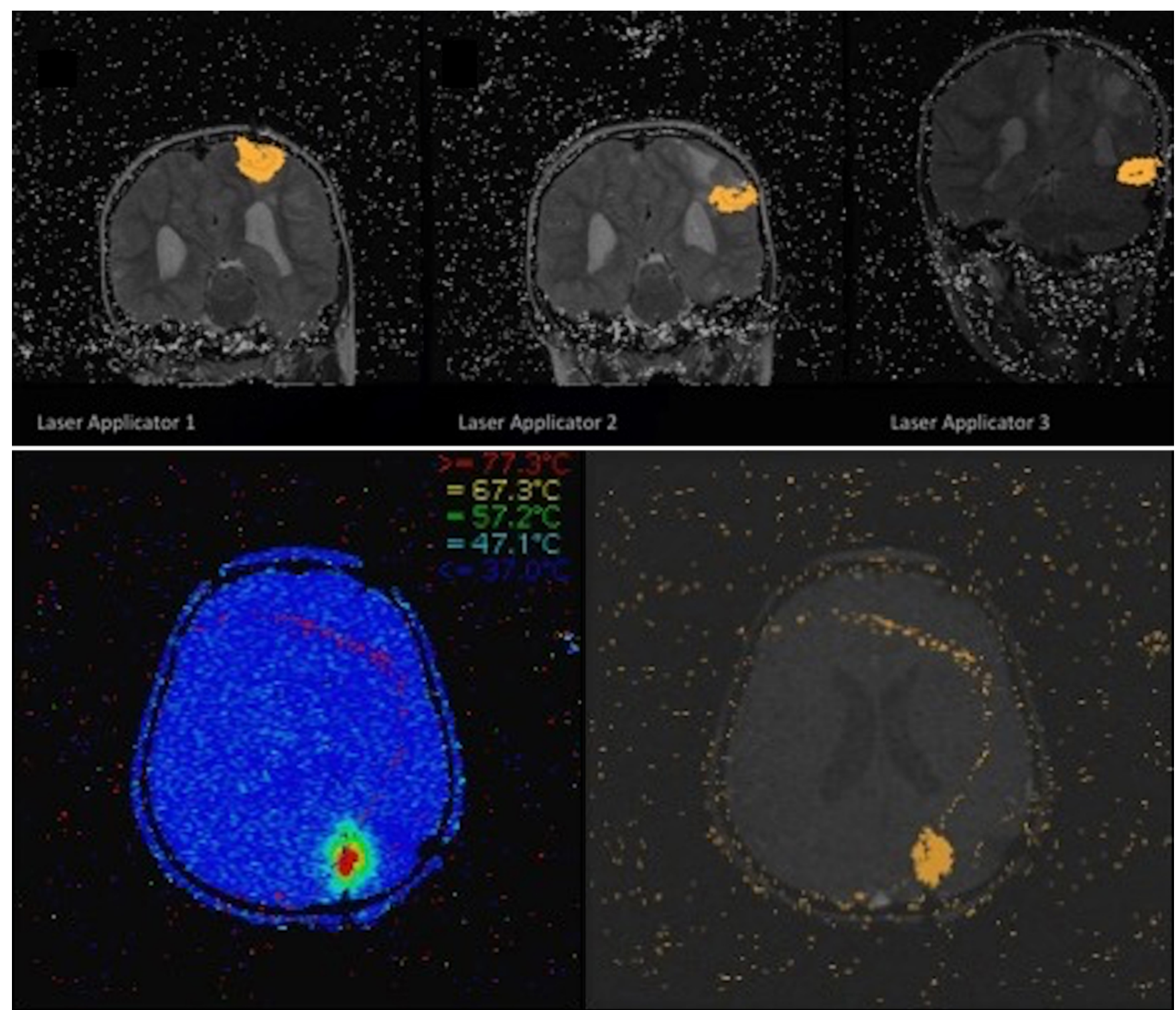

FIG. 3. Illustrative case (patient 1). Upper: Estimated damage map of 3 laser trajectories in first staged procedure. Lower: Estimated damage map of the single occipital trajectory in second staged procedure.

laser ablation in a single stage. The use of SEEG-guided thermocoagulation for epileptic foci has been described previously. ${ }^{19}$ To our knowledge, the use of this technique for patients with tuberous sclerosis has not yet been described and deserves further study.

Even in patients with multiple tubers, seizures may still arise from a single tuber. An epileptogenic tuber is not necessarily the largest tuber, though it could be in some cases. In any event, it may be difficult to identify, by only observing the surface of the brain, the exact tuber that was presurgically diagnosed as epileptogenic, ${ }^{8}$ and ablation of the specific tuber under MRI visualization may be advantageous for this reason.

Cortical tubers originate between 7 and 12 weeks of human gestation, primarily as the result of a disorder of neural proliferation. ${ }^{3}$ They are generally located at the gray/white matter edge, multiple in number, and often as- sociated with multiple epileptic foci. Tubers situated in the temporal and occipital cerebral lobes, areas of the brain which develop earlier, can become epileptogenic before other cortical lesions in the same patient. ${ }^{28}$ Tubers differ morphologically and functionally even in the same patient, which might explain the different susceptibility of individual tubers to seizure onset and diffusion. ${ }^{9}$ According to some authors, cyst-like cortical tubers may contribute to the more severe epilepsy profile seen in TSC patients with these lesions. ${ }^{7}$ Quadrants containing the greatest tuber burden, increased tuber size, and tuber calcifications were not found to be predictive of regional interictal epileptiform activity. ${ }^{7,17}$

Magnetic resonance-guided laser interstitial thermal therapy (MRgLITT) has been shown to be a safe and effective alternative to traditional neurosurgery in the setting of not only epilepsy surgery but also neuro-oncolo- 


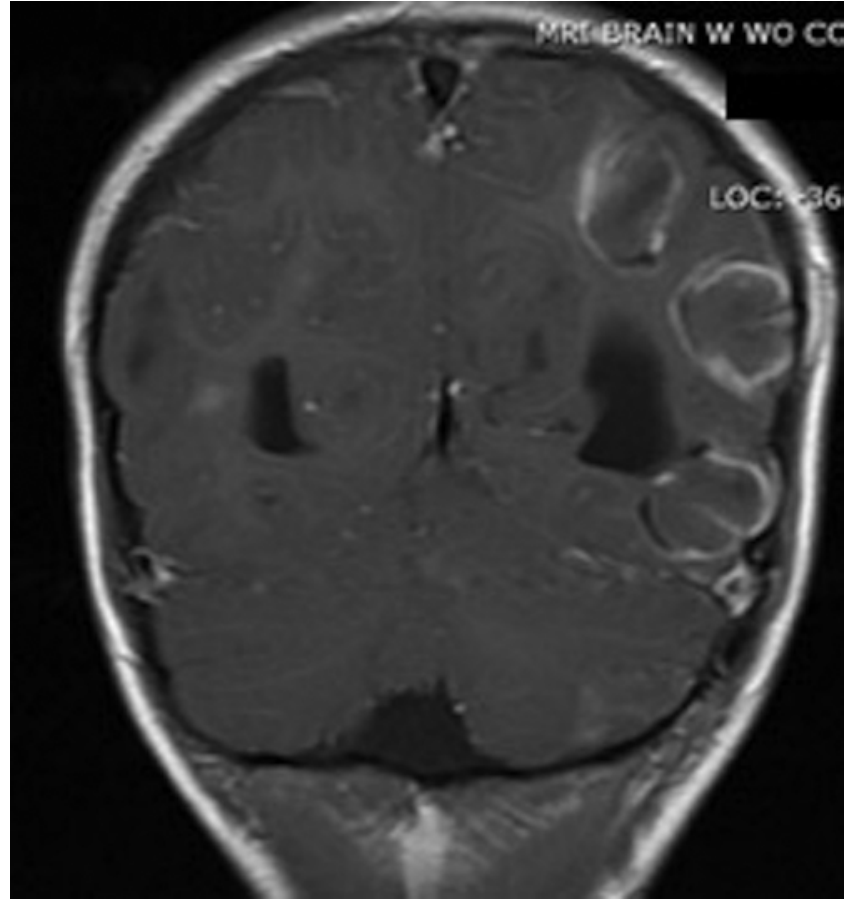

FIG. 4. Illustrative case (patient 1). Postoperative contrast-enhanced T1 MR image obtained 3 months after LITT showing ablated regions.

gy. 4,5,13,20,25,40,41 Laser ablation offers additional benefit in that it is a minimally invasive technique and can provide a surgical cure in a patient who would otherwise not be deemed a candidate for surgical treatment. Furthermore, when compared to radioablation, there is no known risk of radiation necrosis or secondary malignancy. ${ }^{12}$ Laser ablation is associated with shorter hospital stays, minimal pain, faster recovery, improved cosmetic outcomes, and delivery of a surgical cure while minimizing the disruption of family life. ${ }^{24}$

Introduced by Achslogh in 1964, surgery has been described as an option for treatment of intractable epilepsyrelated with tuberous sclerosis. ${ }^{22}$ Classic surgical options for these patients include resection of the epileptic focus, corpus callosotomy, and vagal nerve stimulation. $8,30,32$ Open surgical resection is the current standard of care for patients with medically refractory seizures due to cortical tubers. Surgical excision of a single cortical tuber, localized in non-eloquent areas and coinciding with the EEG evidence of ictal onset, has the best chance to obtain total seizure control. However, patients with TSC and epilepsy often present with bilateral and multiple cortical tubers, ${ }^{30}$ making surgical treatment challenging and increasing the risk of adverse effects. As previously stated, some authors have suggested that the perituberal cortex should also be removed since the epileptogenicity may derive from the perturbation or abnormal development of the surrounding cortex rather than the tuber itself. ${ }^{27,29,30,36}$ The literature for TSC is limited to retrospective case series, demonstrating a range of approaches for preoperative evaluation and treatment. ${ }^{8}$ Most recent series have used some combination of MRI, PET, and SPECT for imaging. Scalp EEG, with or without magnetoencephalography (MEG), and intra- cranial invasive EEG monitoring are also used to define the epileptogenic tuber further. Improvements in imaging and EEG techniques have allowed for better localization and more accurate resections. Several series have reported equal if not better seizure outcomes without the use of invasive EEG; however, to date it is difficult to evaluate the value of invasive EEG monitoring and extent of resection without the benefit of data from a larger, prospective, and standardized cohort. ${ }^{27,29,36}$

The alternative of a minimally invasive approach such as MRgLITT broadens the option of surgical treatment to include patients with reduced quality of life who traditionally would not have met criteria for open surgery. In particular, this includes very young patients who generally present with catastrophic epileptic syndrome associated with developmental delay and regression. Laser ablation also offers surgical candidacy to patients with multiple epileptogenic cortical tubers as shown here. Aggressive and early surgical treatment is associated with significant control of epilepsy, improved cognition and learning capabilities, and better quality of life for patients and their families. ${ }^{33}$

Reports of seizure freedom rates varied substantially from $0 \%$ in 2 individual case reports to $100 \%$ in a series of 10 cases (average of 55\%). ${ }^{6,14,33}$ The discrepancy in the outcomes of the reported series reflects the disparity of the variables that were analyzed, such as age at epilepsy onset or age at surgery, different clinical features, and various presurgical evaluations and surgical procedures. ${ }^{30}$ In a systematic review, Jansen et al. reported that seizure freedom was achieved for $57 \%$ of patients and seizure frequency improved by $90 \%$ in another $18 \%$ of patients; thus they considered that good seizure control was achieved in $75 \%$ of cases. ${ }^{22}$ The seizure freedom rate has significantly improved in the last 5 years, leading to a $63 \%$ rate of Engel class I status. This is probably due to the recent technical advances in the localization of the epileptogenic zone. ${ }^{28}$

In our series of 7 patients with TSC, MRgLITT delivered a seizure freedom rate similar to that achieved with resective surgery. Seizure freedom was reported in $43 \%$ of our cases, which is comparable to the average rate $50 \%-$ $56.8 \%$ reported for resective surgery in the recent literature. ${ }^{1,6,14,33}$ All of our patients had a meaningful reduction in seizure frequency reported by Engel and ILAE seizure outcome. A majority (71.4\%) of our patients experienced a reduction in AED burden, compared with $62.5 \%$ in another series. ${ }^{1}$ Historically, poor outcome in TSC surgery is associated with early age of seizure onset, history of infantile spasms, and multifocal interictal activity. ${ }^{27}$ Laser ablation offers the possibility of surgical treatment as early as the epileptogenic focus or tubers are identified without excluding the option for further surgery later on in life if new tubers become active.

About half of the patients with TSC present with some behavioral difficulties during development, such as classic infantile autism and autism spectrum disorder. ${ }^{10,23}$ Other common behavioral manifestations include anxiety, depression, aggression, and sleep disorders. ${ }^{11}$ Four of our patients presented with behavioral issues, namely selfaggression, autistic features, and attention deficits. As previously mentioned, these symptoms improved after laser 
ablation and the resulting improvement in seizure control, although we do not have data from formal neuropsychological evaluation to support these observations. No patient died, and no morbidity related to the procedure was reported even when a large volume of ablation per procedure was achieved. Moreover, there were no surgical infections in our case series-a rate of $0 \%$, in comparison with the rates in the open staged surgical series of $1.5 \%$ for CNS or flap infections, $5.5 \%$ for positive cultures, and $3 \%$ for wound complications..$^{15,16}$

Although there were no complications to describe in our 7 cases, others have reported individual cases of transient and long-term complications with laser ablation. In one series, a transient third or fourth cranial nerve palsy occurred due to thermal spread in treating epilepsy-related medial temporal sclerosis, as reported by Wicks et al. ${ }^{41}$ Lewis et al. reported a delayed intracranial hemorrhage following MRgLITT for lesional epilepsy, possibly due to pseudoaneurysm formation related to thermal injury. ${ }^{2}$ One pediatric epilepsy case series noted transient hydrocephalus in one patient and cerebral edema responsive to dexamethasone in another. ${ }^{26}$ These few complications emphasize the need for careful surgical planning and a specialized epilepsy surgery team as well as the importance of formal training in functional neurosurgery and, foremost, the required mentoring and hands-on experience in applying the MRgLITT technology as previously described. ${ }^{37}$

\section{Conclusions}

Tuberous sclerosis continues to represent a significant burden as a source of intractable epilepsy in more than $80 \%$ of affected patients. Only about one-third of these patients become surgical candidates. Lesionectomy and tuberectomy, including resection of the peri-tuberal area, provide more than $50 \%$ of patients with seizure freedom with the added benefit of cognitive and behavioral improvement related to the seizure control, which is especially significant when the patient is treated at an early age.

Our series is the most significant case series to date showing the successful utilization of MRgLITT for treating cortical tubers in pediatric patients with refractory TSC epilepsy. MRgLITT represents a minimally invasive surgical option that reduces the risk and complications of resective epilepsy surgery, especially in the multi-staged cases. Further multi-institutional studies using standardized protocols are required for long-term evaluations of seizure, behavioral, and cognitive improvement in these patients.

\section{References}

1. Arya R, Tenney JR, Horn PS, Greiner HM, Holland KD, Leach JL, et al: Long-term outcomes of resective epilepsy surgery after invasive presurgical evaluation in children with tuberous sclerosis complex and bilateral multiple lesions. J Neurosurg Pediatr 15:26-33, 2015

2. Barber SM, Tomycz L, George T, Clarke DF, Lee M: Delayed intraparenchymal and intraventricular hemorrhage requiring surgical evacuation after MRI-guided laser interstitial thermal therapy for lesional epilepsy. Stereotact Funct Neurosurg 95:73-78, 2017

3. Barkovich AJ, Kuzniecky RI, Jackson GD, Guerrini R,
Dobyns WB: A developmental and genetic classification for malformations of cortical development. Neurology 65:18731887,2005

4. Carpentier A, Chauvet D, Reina V, Beccaria K, Leclerq D, McNichols RJ, et al: MR-guided laser-induced thermal therapy (LITT) for recurrent glioblastomas. Lasers Surg Med 44:361-368, 2012

5. Choi H, Tovar-Spinoza Z: MRI-guided laser interstitial thermal therapy of intracranial tumors and epilepsy: state-ofthe-art review and a case study from pediatrics. Photonics Lasers Med 3:107, 2014

6. Chu-Shore CJ, Major P, Camposano S, Muzykewicz D, Thiele EA: The natural history of epilepsy in tuberous sclerosis complex. Epilepsia 51:1236-1241, 2010

7. Chu-Shore CJ, Major P, Montenegro M, Thiele E: Cyst-like tubers are associated with TSC2 and epilepsy in tuberous sclerosis complex. Neurology 72:1165-1169, 2009

8. Connolly MB, Hendson G, Steinbok P: Tuberous sclerosis complex: a review of the management of epilepsy with emphasis on surgical aspects. Childs Nerv Syst 22:896-908, 2006

9. Curatolo P: Intractable epilepsy in tuberous sclerosis: is the tuber removal not enough? Dev Med Child Neurol 52:987, 2010

10. Curatolo P, Porfirio MC, Manzi B, Seri S: Autism in tuberous sclerosis. Eur J Paediatr Neurol 8:327-332, 2004

11. Curatolo P, Verdecchia M, Bombardieri R: Tuberous sclerosis complex: a review of neurological aspects. Eur J Paediatr Neurol 6:15-23, 2002

12. Diaz R, Ivan ME, Hanft S, Vanni S, Manzano G, Jagid J, et al: Laser interstitial thermal therapy: lighting the way to a new treatment option in neurosurgery. Neurosurgery 79 (Suppl 1):S3-S7, 2016

13. Esquenazi Y, Kalamangalam GP, Slater JD, Knowlton RC, Friedman E, Morris SA, et al: Stereotactic laser ablation of epileptogenic periventricular nodular heterotopia. Epilepsy Res 108:547-554, 2014

14. Evans LT, Morse R, Roberts DW: Epilepsy surgery in tuberous sclerosis: a review. Neurosurg Focus 32(3):E5, 2012

15. Fallah A, Guyatt GH, Snead OC III, Ebrahim S, Ibrahim GM, Mansouri A, et al: Predictors of seizure outcomes in children with tuberous sclerosis complex and intractable epilepsy undergoing resective epilepsy surgery: an individual participant data meta-analysis. PLoS One 8:e53565, 2013

16. Fallah A, Rodgers SD, Weil AG, Vadera S, Mansouri A, Connolly MB, et al: Resective epilepsy surgery for tuberous sclerosis in children: determining predictors of seizure outcomes in a multicenter retrospective cohort study. Neurosurgery 77:517-524, 2015

17. Gallagher A, Chu-Shore CJ, Montenegro MA, Major P, Costello DJ, Lyczkowski DA, et al: Associations between electroencephalographic and magnetic resonance imaging findings in tuberous sclerosis complex. Epilepsy Res 87:197202, 2009

18. Gascoigne MB, Smith ML, Barton B, Webster R, Gill D, Lah $\mathrm{S}$ : Attention deficits in children with epilepsy: Preliminary findings. Epilepsy Behav 67:7-12, 2017

19. Guénot M, Isnard J, Ryvlin P, Fischer C, Mauguière F, Sindou M: SEEG-guided RF thermocoagulation of epileptic foci: feasibility, safety, and preliminary results. Epilepsia 45:1368-1374, 2004

20. Hawasli AH, Bagade S, Shimony JS, Miller-Thomas M, Leuthardt EC: Magnetic resonance imaging-guided focused laser interstitial thermal therapy for intracranial lesions: singleinstitution series. Neurosurgery 73:1007-1017, 2013

21. Holmes GL, Stafstrom CE: Tuberous sclerosis complex and epilepsy: recent developments and future challenges. Epilepsia 48:617-630, 2007

22. Jansen FE, van Huffelen AC, Algra A, van Nieuwenhuizen 
O: Epilepsy surgery in tuberous sclerosis: a systematic review. Epilepsia 48:1477-1484, 2007

23. Jeste SS, Sahin M, Bolton P, Ploubidis GB, Humphrey A: Characterization of autism in young children with tuberous sclerosis complex. J Child Neurol 23:520-525, 2008

24. Jimenez-Ruiz F, Arnold B, Tatsui CE, Cata JP: Perioperative and anesthetic considerations for neurosurgical laser interstitial thermal therapy ablations. J Neurosurg Anesthesiol 30:10-17, 2018

25. Kang JY, Wu C, Tracy J, Lorenzo M, Evans J, Nei M, et al: Laser interstitial thermal therapy for medically intractable mesial temporal lobe epilepsy. Epilepsia 57:325-334, 2016

26. Lewis EC, Weil AG, Duchowny M, Bhatia S, Ragheb J, Miller I: MR-guided laser interstitial thermal therapy for pediatric drug-resistant lesional epilepsy. Epilepsia 56:1590-1598, 2015

27. Madhavan D, Schaffer S, Yankovsky A, Arzimanoglou A, Renaldo F, Zaroff CM, et al: Surgical outcome in tuberous sclerosis complex: a multicenter survey. Epilepsia 48:16251628,2007

28. Moavero R, Cerminara C, Curatolo P: Epilepsy secondary to tuberous sclerosis: lessons learned and current challenges. Childs Nerv Syst 26:1495-1504, 2010

29. Moshel YA, Elliott R, Teutonico F, Sellin J, Carlson C, Devinsky O, et al: Do tubers contain function? Resection of epileptogenic foci in perirolandic cortex in children with tuberous sclerosis complex. Epilepsia 51:1242-1251, 2010

30. Novegno F, Di Rocco C: Tuberous sclerosis, in Di Rocco C, Pang D, Rutka JT (eds): Textbook of Pediatric Neurosurgery. Cham: Springer, 2017

31. Prasad V, Kendrick D, Sayal K, Thomas SL, West J: Injury among children and young adults with epilepsy. Pediatrics 133:827-835, 2014

32. Romanelli P, Verdecchia M, Rodas R, Seri S, Curatolo P: Epilepsy surgery for tuberous sclerosis. Pediatr Neurol 31:239-247, 2004

33. Roth J, Olasunkanmi A, MacAllister WS, Weil E, Uy CC, Devinsky O, et al: Quality of life following epilepsy surgery for children with tuberous sclerosis complex. Epilepsy Behav 20:561-565, 2011

34. Saxena A, Sampson JR: Epilepsy in tuberous sclerosis: phenotypes, mechanisms, and treatments. Semin Neurol 35:269-276, 2015

35. Sillanpää M, Shinnar S: Long-term mortality in childhoodonset epilepsy. N Engl J Med 363:2522-2529, 2010

36. Teutonico F, Mai R, Devinsky O, Lo Russo G, Weiner HL, Borrelli P, et al: Epilepsy surgery in tuberous sclerosis com- plex: early predictive elements and outcome. Childs Nerv Syst 24:1437-1445, 2008

37. Tovar-Spinoza Z, Carter D, Ferrone D, Eksioglu Y, Huckins $\mathrm{S}$ : The use of MRI-guided laser-induced thermal ablation for epilepsy. Childs Nerv Syst 29:2089-2094, 2013

38. Tovar-Spinoza Z, Choi H: Magnetic resonance-guided laser interstitial thermal therapy: report of a series of pediatric brain tumors. J Neurosurg Pediatr 17:723-733, 2016

39. van Eeghen AM, Chu-Shore CJ, Pulsifer MB, Camposano SE, Thiele EA: Cognitive and adaptive development of patients with tuberous sclerosis complex: a retrospective, longitudinal investigation. Epilepsy Behav 23:10-15, 2012

40. Waseem H, Vivas AC, Vale FL: MRI-guided laser interstitial thermal therapy for treatment of medically refractory nonlesional mesial temporal lobe epilepsy: outcomes, complications, and current limitations: a review. J Clin Neurosci 38:1-7, 2017

41. Wicks RT, Jermakowicz WJ, Jagid JR, Couture DE, Willie JT, Laxton AW, et al: Laser interstitial thermal therapy for mesial temporal lobe epilepsy. Neurosurgery 79 (Suppl 1):S83-S91, 2016

\section{Disclosures}

Dr. Tovar-Spinoza reports a consultant relationship with Monteris.

\section{Author Contributions}

Conception and design: Tovar-Spinoza. Acquisition of data: Zyck. Analysis and interpretation of data: Zyck. Drafting the article: Ziechmann. Critically revising the article: Tovar-Spinoza, Zyck. Reviewed submitted version of manuscript: all authors. Approved the final version of the manuscript on behalf of all authors: TovarSpinoza. Study supervision: Tovar-Spinoza.

\section{Supplemental Information \\ Videos \\ Video Abstract. https://vimeo.com/283455602.}

\section{Correspondence}

Zulma Tovar-Spinoza: SUNY Upstate Medical University, Syracuse,NY.tovarspz@upstate.edu. 